\title{
Testing of the Structure and Mechanical Properties of Technical Titanium Joints
}

\author{
Bogumil Wronka \\ Faculty of Civil Engineering, Mechanics and Petrochemistry, Institute of Mechanical Engineering, Warsaw University of Technology, \\ Ulica Eukasiewicza 17, 09-400 Płock, Poland \\ Correspondence should be addressed to Bogumił Wronka; wronkab@pw.plock.pl
}

Received 25 May 2013; Accepted 7 June 2013

Academic Editor: Marcel Ausloos

Copyright (C) 2013 Bogumił Wronka. This is an open access article distributed under the Creative Commons Attribution License, which permits unrestricted use, distribution, and reproduction in any medium, provided the original work is properly cited.

\begin{abstract}
The aim of the research was the titanium pipeline welding technology. The transformations of this material due to the influence of thermal welding were analysed. The basic purpose was to evaluate the properties of titanium joint areas. Pipe joints of various thicknesses were welded by means of TIG argon arc welding while applying the optimum and reduced gas flow intensities. The structure and mechanical properties of these joints were tested. Different test results were obtained for joints welded in these two conditions. Recommendations concerning the welding technology and the heat treatment of joints after welding were presented.
\end{abstract}

\section{Introduction}

Titanium and its alloys occupy an important place among metal constructional materials due to their especially valuable physical and chemical properties [1-3] which include small specific gravity and big strength in normal and raised temperatures. These materials are highly resistant to atmospheric corrosion and various aggressive environments. Therefore, due to their properties, titanium and its alloys find multiple applications in construction of installations, pipelines, and chemical equipment [4-6], as, for example, a reactor made of an explosively clad steel titanium sheet (Figure 1$)[7,8]$ or a welded technical titanium pipeline.

Technical titanium in comparison to the chemically pure element is usually foul with oxygen, nitrogen, hydrogen, carbon, iron, silicon, and other elements. The amount of these impurities generally amounts to $0.2-1.2 \%$. These tramp elements form with pure titanium respective binary diagrams of equilibrium systems (Figure 2) [9].

Technical titanium and titanium single-phase alloys $\alpha$ belong to one group. The content of elements stabilizing the phase $\beta$ is small and does not exceed a boundary value in the phase $\alpha$. Thus the structure of these alloys after exerting plastic strain and annealing consists mainly of the solid solution $\alpha$ (>95\%).
In the case of pure titanium the temperature of the allotropic transformation $\mathrm{Ti}_{\alpha} \rightleftharpoons \mathrm{Ti}_{\beta}$ equals $1155.5 \mathrm{~K}$. During heating, in these conditions, the unit cell $\mathrm{Ti}_{\alpha}$ with a hexagonal lattice transforms into the cell $\mathrm{Ti}_{\beta}$ which crystallizes into a regular centric lattice system. During cooling, a complete reverse transformation $\mathrm{Ti}_{\beta} \rightarrow \mathrm{Ti}_{\alpha}$ occurs. At small heating and cooling rates the transformation $\mathrm{Ti}_{\alpha} \rightleftharpoons \mathrm{Ti}_{\beta}$ develops by means of nucleation of a new phase and an increase of nucleuses (diffusion). Heating of semifinished titanium products above the allotropic transformation temperature $(\alpha-\beta)$ always leads to the growth of grains independently of heating or cooling.

When cooling from the phase $\beta$ stability temperature is fast, then the transformation $\mathrm{Ti}_{\beta} \rightarrow \mathrm{Ti}_{\alpha}$ becomes martensitic with shear mechanism $\left(\beta \rightarrow \alpha^{\prime}\right)$. Titanium martensite is a metastable phase, and it is formed as a result of the lattice strain [10]. The martensitic phase $\alpha^{\prime}$ crystallizes into a hexagonal lattice system and determines the supersaturated substitutional solid solution of elements in $\mathrm{Ti}_{\alpha}$. Beside heating and cooling conditions, the martensite morphology depends on the initial heat and plastic treatment. Depending on structure, large areas with twin crystals and needles or plates with different arrangements typical of the phase $\alpha^{\prime}$ can be distinguished. 


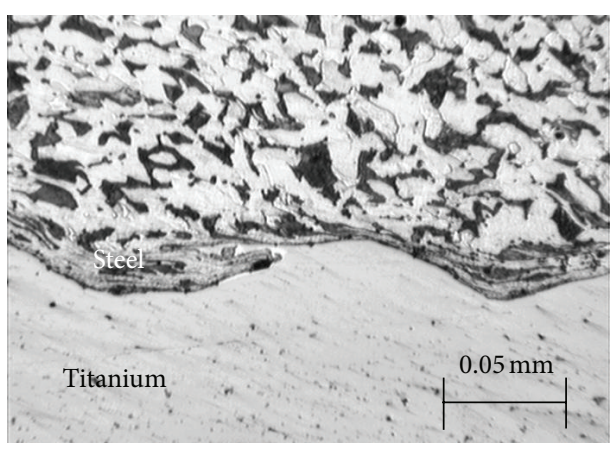

(a)

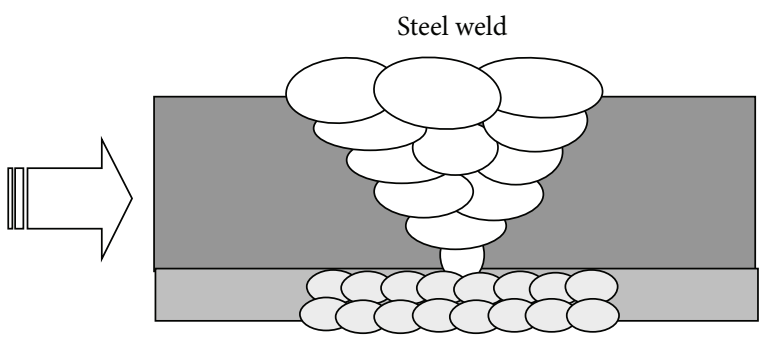

Titanium weld

(b)

FIGURE 1: The explosively clad steel titanium sheet before (a) and after welding (b) in the reactor.

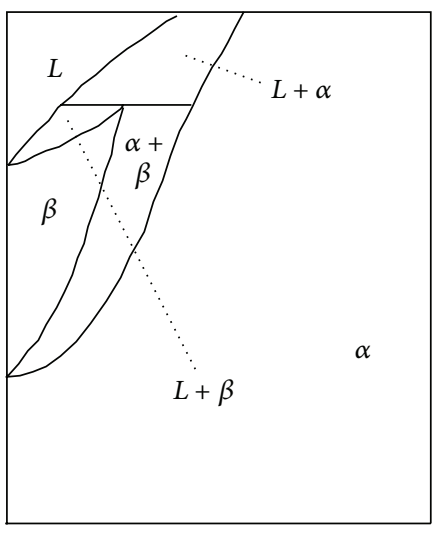

$\mathrm{O}^{*}, \mathrm{~N}^{*}$

${ }^{*}$ The elements of technical titanium

(a)

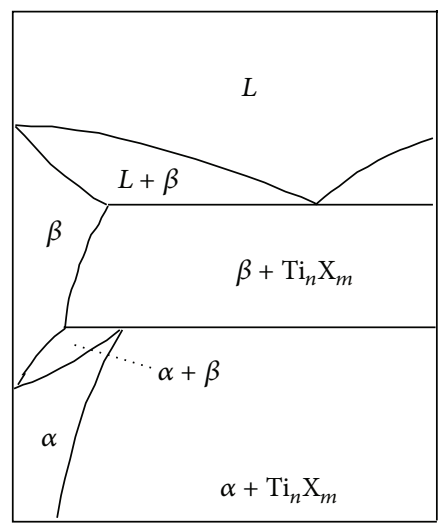

$\mathrm{C}^{*}, \mathrm{~B}, \mathrm{Ce}, \mathrm{Ca}, \mathrm{Ge}, \mathrm{Ga}, \mathrm{Sn}, \mathrm{Nd}, \mathrm{Y}$

${ }^{*}$ The elements of technical titanium

(b)

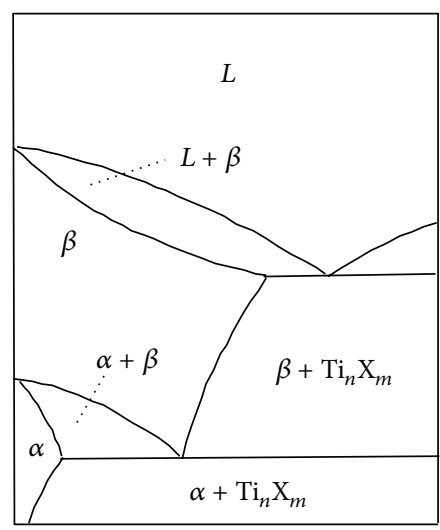

$\mathrm{H}^{*}, \mathrm{Fe}^{*}, \mathrm{Si}, \mathrm{Mn}, \mathrm{Co}, \mathrm{Ni}, \mathrm{Au}, \mathrm{Pd}, \mathrm{Pt}$

${ }^{*}$ The elements of technical titanium

(c)

FIGURE 2: The binary diagrams of equilibrium systems on the titanium matrix: systems with elements creating only a peritectic transformation (a), systems with elements in which both eutectic and peritectoid transformations occur (b), and systems with elements in which both eutectic and eutectoid transformations occur (c).

In the case of technical titanium the transformation $\mathrm{Ti}_{\beta} \rightarrow \mathrm{Ti}_{\alpha}$ takes place at a higher temperature ranging from 1133 to $1233 \mathrm{~K}$. Its structure contains a small quantity of the phase $\beta$ owing to hydrogen and iron, which are within their equilibrium solubility in the phase $\alpha$. The particles of the phase $\beta$ limit the plate growth of the phase $\alpha$.

Titanium shows especially high affinity to oxygen in a solid and liquid state at temperatures above $773 \mathrm{~K}$. Nitrogen increases titanium's strength more than oxygen and carbon. Hydrogen increases titanium's brittleness.

\section{The Weldability of Technical Titanium}

Due to its high thermal efficiency of remelting during welding, titanium undergoes a different welding thermal cycle as compared to steel. The basic problem concerns good plasticity of the welded joint which depends on the welded structure and the phase transformations occurring in the heat-affected zone at temperatures above the transformation $\alpha+\beta \rightarrow \beta$. The welding process requires high accuracy because of strong chemical activity of oxygen, nitrogen, and hydrogen in the heated joint area.

In the case of single-phase alloys $\alpha$ the growth of columnar crystals begins from the melted grains of the base material. The phase transformation $\beta \rightarrow \alpha$ during cooling of welded joints enables the dendritic structure of the weld. The phase transformation of titanium and its physical properties determine the structural change in the various volumes of the heat-affected zone (Figure 3(a)). The heat-affected zone is characterized by nonuniform heating of each of the alloy volumes. It causes the heterogenous state of stress, strain, phase transformations, and structural changes. The differences in the cooling and annealing rates in the heataffected zones for various thicknesses of the welded elements $\delta_{1}, \delta_{2}$ are presented in Figure 3(b).

The heat-affected zone of a joint contains areas of incomplete weld penetration, a complete phase transformation, a partial recrystallization, and a recrystallization. In the first two areas grain growth occurs, as well as the segregation of elements and an increase in the gas content. Grain sizes depend on a maximum heating temperature, the exposure 


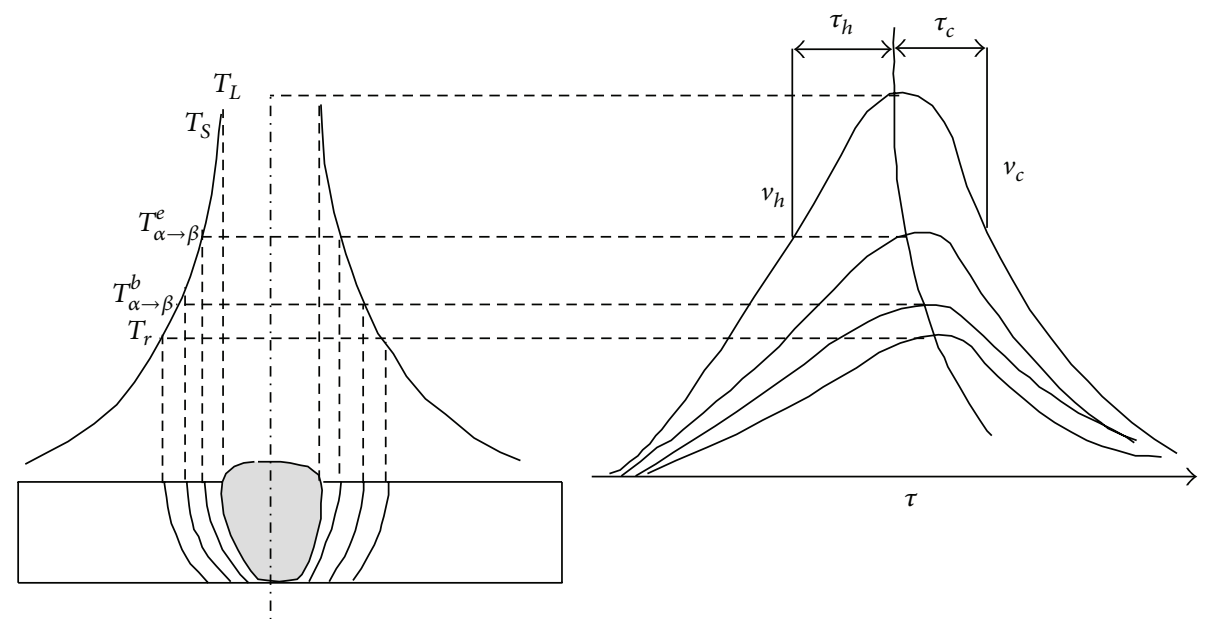

(a)

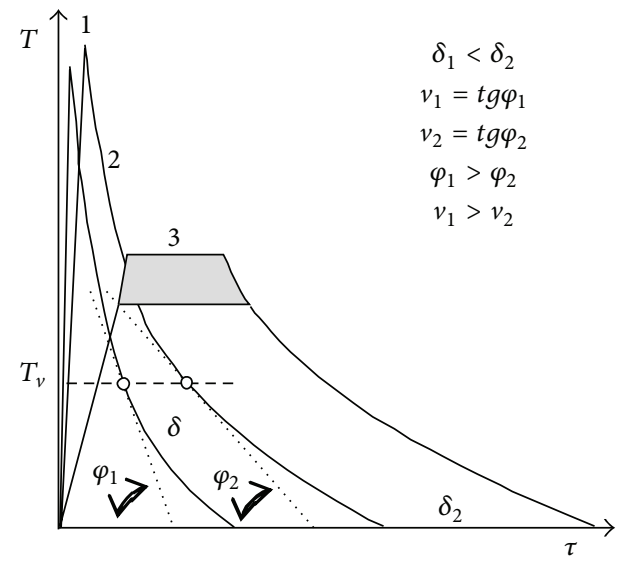

(b)

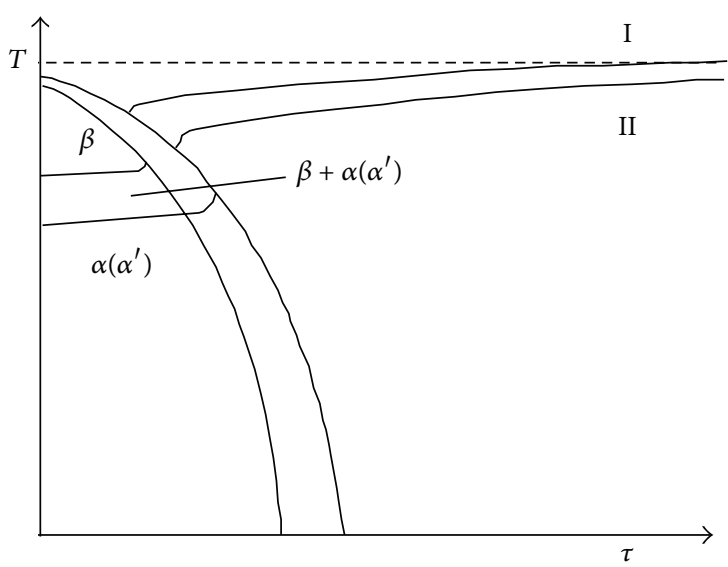

(c)

FIGURE 3: The structure of the heat-affected zone (a): $T_{L}, T_{S}$, and $T_{r}$ are the temperatures of liquidus, solidus, and recrystallization, respectively; $T_{\alpha \rightarrow \beta}^{b}$ and $T_{\alpha \rightarrow \beta}^{e}$ are the temperatures at the beginning and the end of the phase transformation $\alpha \rightarrow \beta$; $\tau_{h}$ is the heating time from $T_{\alpha \rightarrow \beta}^{e}$ to $T_{L} ; \tau_{c}$ is the cooling time from $T_{L}$ to $T_{\alpha \rightarrow \beta}^{e} ; v_{h}$ and $v_{c}$ are the heating and cooling rates during the phase transformation. The weld thermal cycles 1, 2 and the annealing cycle $3(\mathrm{~b}): \delta_{1}$ and $\delta_{2}$ are thicknesses of the welded elements; $v_{1}$ and $v_{2}$ are the cooling rates of the welds in the temperature $T_{v}$. The phase transformation diagram during welding of technical titanium (c): I is the beginning of the transformation $\beta \rightarrow \alpha^{\prime}$, and II is the end of the transformation $\beta \rightarrow \alpha\left(\alpha^{\prime}\right)$.

time to temperature above the phase transformation $\alpha \rightarrow$ $\beta$, and the heating and cooling rates. The typical phase transformation diagram during the welding of technical titanium is shown in Figure 3(c).

The area of a partial recrystallization $\left(T_{\alpha \rightarrow \beta}^{e}-T_{\alpha \rightarrow \beta}^{b}\right)$ (Figure 3(a)) shows a smaller grain growth, since the temperature range is small. The structure of this area consists of phases $\alpha+\alpha^{\prime}$. The structure of the recrystallization area consists mostly of the phase $\alpha$ grains of a small diameter (the equiaxed structure) without any signs of phase transformations.

The recrystallization area gradually joins the base material structure. For the temperatures ranging from 623 to $663 \mathrm{~K}$ the heat-affected zone can include hydrides TiH separated at the grains boundaries, along the slip lines and the twin crystals. The welds including only elements stabilizing the phase $\alpha$ are of homogeneous structure consisting of the martensitic phase $\alpha^{\prime}$. The elements stabilizing the phase $\beta$ improve the hydrogen embrittlement resistance in the joint.

The welding wire should have a specified strength and plasticity. The temperature of the phase transformation $\alpha \rightarrow$ $\beta$ in the wire material should always be higher than the temperature transformation in the base material. Thus the weld material should remain in the annealed state after carrying out the heat treatment of the base material.

The single-phase titanium $\alpha$ is characterized by good weldability. A change in the linear energy of welding little influences the plastic and strength properties of the weld and the heat-affected zone. The main factor determining the plastic properties of the weld is the cooling rate of these zones. For the alloys $\alpha$ after plastic strain, the important factor is also the exposure time of the base material to temperatures 
TABLE 1: The chemical constitution of the material from the titanium pipes and the filler metal.

\begin{tabular}{lcccccc}
\hline$\delta$ & \multicolumn{6}{c}{ Chemical constitution, \% } \\
& $\mathrm{O}$ & $\mathrm{N}$ & $\mathrm{C}$ & $\mathrm{H}$ & $\mathrm{Fe}$ & $\mathrm{Ti}$ \\
\hline$\delta_{2}$ & 0.162 & 0.003 & 0.003 & 0.003 & 0.030 & $\mathrm{Bal}$ \\
$\delta_{1}$ & 0.110 & 0.006 & 0.012 & 0.008 & 0.060 & $\mathrm{Bal}$ \\
Filler metal & 0.090 & 0.005 & 0.010 & 0.005 & 0.030 & $\mathrm{Bal}$ \\
\hline
\end{tabular}

TABLE 2: The mechanical properties of the material from the titanium pipes and the filler metal.

\begin{tabular}{lccc}
\hline$\delta$ & $\begin{array}{c}\text { Yield stress, } \\
\mathrm{MPa}\end{array}$ & $\begin{array}{c}\text { Tensile stress } \sigma_{b}, \\
\mathrm{MPa}\end{array}$ & $\begin{array}{c}\text { Elongation, } \\
\varepsilon_{b}, \%\end{array}$ \\
\hline$\delta_{2}$ & 357 & 506 & 34 \\
$\delta_{1}$ & 284 & 513 & 33 \\
Filler metal & 275 & 305 & 20 \\
\hline
\end{tabular}

$\sigma_{b}$ and $\varepsilon_{b}$ are the tensile stress and elongation for pipe base material.

higher than the recrystallization temperature. The best plastic properties of welds were obtained when applying the average and high cooling rates at which the intensity of the grain growth is smaller.

For technical titanium various fusion welding methods are applied. The universal method is TIG argon arc welding [2]. The electron beam welding [11] and the electroslag welding [12] are also used.

In order to obtain the optimal mechanical and technological properties of welded joints made of titanium $\alpha$ they should be annealed at temperatures ranging from $823 \mathrm{~K}$ to $953 \mathrm{~K}$. The soaking time is $0.33-1 \mathrm{~h}$ for the thickness of $2-50 \mathrm{~mm}$ [13]. Annealing should be carried out above the recrystallization temperature but below the allotropic transformation followed by air cooling. In order to avoid welding stresses underannealing should be applied at temperatures ranging from $723 \mathrm{~K}$ to $773 \mathrm{~K}$ using the soaking time of $0.5-$ 4 hours.

\section{Test Results}

\subsection{The Initial Material and Forming Joints}

3.1.1. The Initial Material for Stub Pipes and the Filler Metal. The initial titanium elements for welding consisted of the segments of pipes with the outer diameter of $355.6 \mathrm{~mm}\left(14^{\prime \prime}\right)$

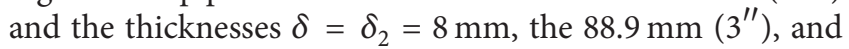
$\delta=\delta_{1}=3.05 \mathrm{~mm}$. The chemical constitution and mechanical properties of the pipe material and the filler metal were in accordance with ASTM B862 Grade 2 and ER Ti2-AWS 5.16, and they are shown in Tables 1 and 2.

In the filler material there is a smaller content of oxygen, but the relation of other elements is similar. In the pipe material of the thickness $\delta_{1}$ there is more hydrogen and iron in comparison to the thickness $\delta_{2}$. The strength and elongation of the filler metal were smaller than that of the pipe material (Table 2).
3.1.2. The Welding Process of the Stub Pipes. The stub pipes were welded by means of TIG argon arc welding of high gas purity (99.975\%). The process of welding was performed by a welder type MagicWave 2200 Job manufactured by the Austrian company Fronius. The range of the current intensity was from 110 to $140 \mathrm{~A}$ for the thickness $\delta_{2}$ and from 70 to $100 \mathrm{~A}$ for the $\delta_{1}$ while the mean voltage was $12 \mathrm{~V}$. The TIG welding torch with a trailing box was equipped with three gas flows protecting, respectively, the face, the root, and the back of the weld. This combination shielded the weld and the heataffected zone against the harmful activity of oxygen, nitrogen, and hydrogen from the air. For the stub pipes of the thickness $\delta_{2}$ the optimum range of the joined gas intensity was $I=I_{\mathrm{opt}}$ $=10-20 \mathrm{l} / \mathrm{min}$.

The joint area in the stub pipes of the thickness $\delta_{1}$ and the fine-grained structure of the initial material were deliberately saturated by the increased activity of the atmospheric air. In order to achieve this, the gas intensity was decreased in the root and back flow, which caused $I<I_{\text {opt }}$. This was to test the influence of an insufficient gas shield on the joint properties.

The other conditions for the experimental joints were the same as at the standard welding of industrial pipelines. The fragments of the equipment used by the Polish firm Mostostal Plock SA for welding the elements of pipelines and the experimental joints are presented in Figure 4.

3.2. The Test Procedures. The welded joints made of technical titanium were tested. The samples for tests were cut out of the welded stub pipes. According to the norm PN-EN ISO 15614-5:2005 (U), which qualifies titanium welding technology, a visual inspection, metallographic examination were conducted as well as hardness, tensile, and bend tests.

The visual inspection was to evaluate the colour of the welded joint and welding defectiveness. Macro- and micrometallographic examinations were conducted through an optical microscope NEOPHOT 2. The samples were etched in the Kroll reagent. From the Vickers hardness testing device HPO 250 the hardness values HV10 were obtained indirectly.

During the tensile test the test, pieces demonstrated plastic deformation rate of $0.0017 \mathrm{~s}^{-1}$ as measured on the testing machine HECKERT UFP 400. After reaching a certain target of yield strength, the stretching rate was increased to $0.0053 \mathrm{~s}^{-1}$. The test piece was a long slip cut out from the wall of a welded stub (Figure 4(c)), thus two flat test pieces of the thickness $\delta_{1}$ and two of the thickness $\delta_{2}$.

In the bend test on the same testing machine four flat test pieces of the thickness $\delta_{1}$ were used and four of the thickness $\delta_{2}$ which were cut out from the stub in the same way as in the case of the tensile test. At each thickness two samples were bent on the face of the joint and two on the root. The diameter of the bending mandrel was $30 \mathrm{~mm}$.

3.3. The Properties of the Welded Joints. The visual inspection discovered the silver color (admissible) of the faces and roots on the joints of the thickness $\delta_{2}$ and the blue color (inadmissible) on the joints of the thickness $\delta_{1}$. Observation did not reveal any craters, cracks, or incomplete fusion. 


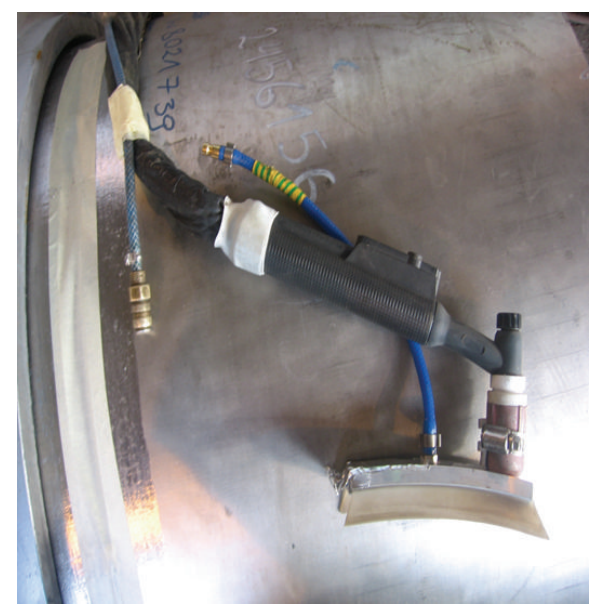

(a)

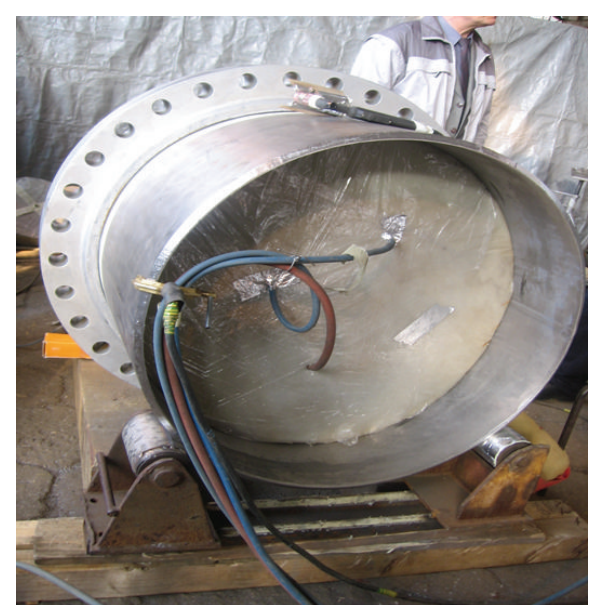

(b)

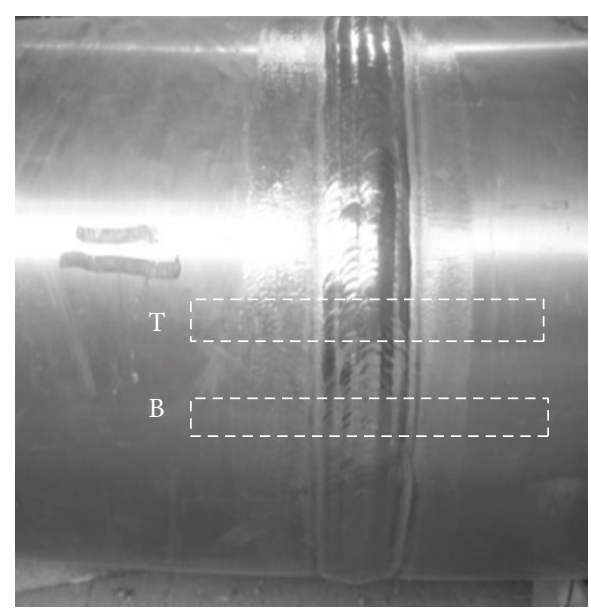

(c)

Figure 4: The torch with a trilling box (a), the stub pipe with a flange on a welding positioner filled with the argon root shield (b), and the tested pipe joint (c): $\mathrm{T}$ and $\mathrm{B}$ are the places where the titanium slips for the test pieces were cut out to take the tensile and bend tests.

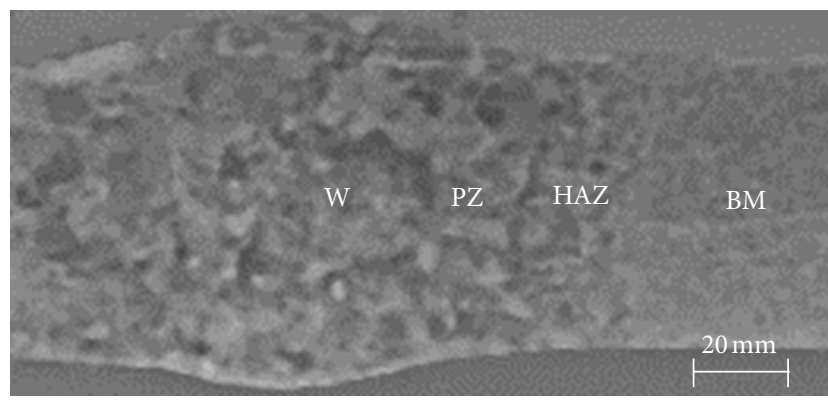

FIGURE 5: The macrostructure of the welded joint of the thickness $\delta_{2}: \mathrm{BM}$ is the base material, $\mathrm{HAZ}$ is the heat-affected zone, $\mathrm{PZ}$ is the penetration zone, and $\mathrm{W}$ is the weld.

The macrostructure of the thickness $\delta_{2}$ joints and its characteristic zones are shown in Figure 5.

The results of microscopic examination are presented in Figures 6 and 7. The base material of the thickness $\delta_{1}$ joint has a little more of the phase $\beta$ and smaller grains than the joint material of the thickness $\delta_{2}$. In both joints the presence of the phases $\alpha, \alpha^{\prime}$, and $\beta$, typical of technical titanium in the initial state and under the influence of the welding thermal cycle, has been revealed. The thinner joints (Figures $7(b)-7(d)$ ) contain a greater quantity of the martensite $\alpha^{\prime}$ than the thicker ones (Figures 6(b)-6(d)), while the weld itself has finer grains.

The hardness numbers and relative hardnesses $h_{1}$ and $h_{2}$ in each joint zone at $I=I_{\mathrm{opt}}$ and $I<I_{\mathrm{opt}}$ are shown in Figure 8. In both cases the relative hardnesses of joints are the highest in the weld. The joints of the thickness $\delta_{1}$ have the greater hardness $H V 10$; therefore for the zones $\mathrm{W}, \mathrm{PZ}$, and HAZ the condition $h_{1}>h_{2}$ is valid.

The tensile test results for the flat samples are presented in Table 3. The joints of the thickness $\delta_{1}$ with fractures in the weld have a bigger tensile strength $\sigma_{j}$. The joints of the thickness $\delta_{2}$ cracked in the heat-affected zone on the penetration zone side. The results of these tests show that for each relative tensile strength index $c_{t}$ there exists the condition $c_{t\left(\delta_{1}\right)}>c_{t\left(\delta_{2}\right)}$. In the case of elongation with 


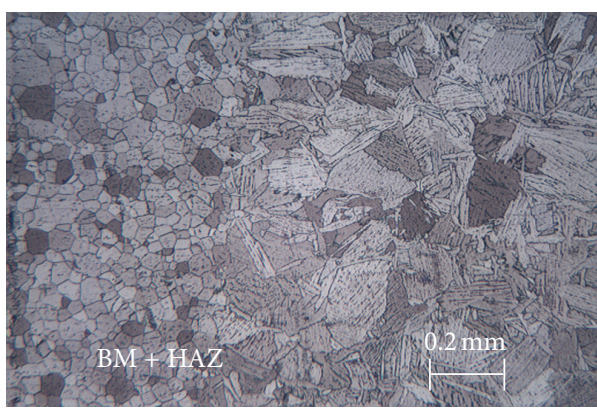

(a)

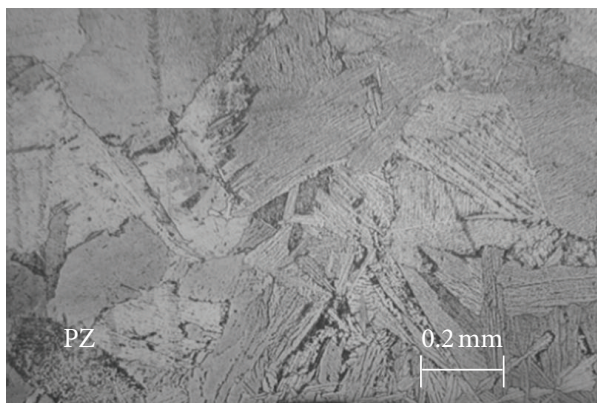

(c)

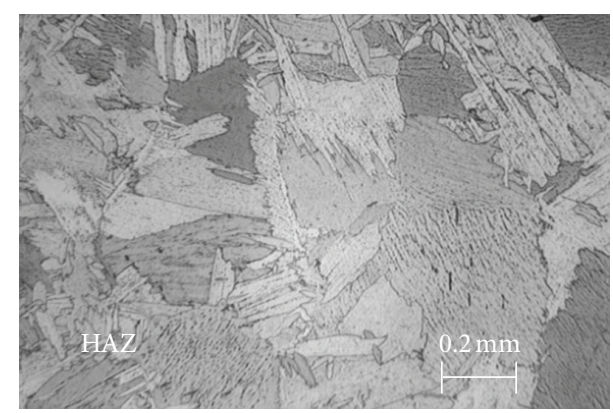

(b)

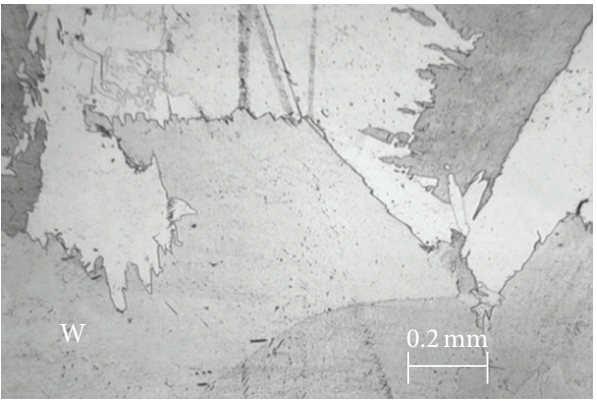

(d)

FIGURE 6: The microstructure of the welded joint of the thickness $\delta_{2}$ at $I=I_{\mathrm{opt}}$ : the structure of the base material after rolling with the phase $\alpha$ coming into the heat-affected zone with thick grains, inclusions of the phase $\beta$ (a); partial or complete recrystallization of the phases $\alpha+\alpha^{\prime}$ and $\beta$ (b); grains of the phases $\alpha+\alpha^{\prime}$ (c); the coarse-grained phases $\alpha$ and $\alpha^{\prime}$ of the weld material (d). The grain sizes are increased towards the weld axis.

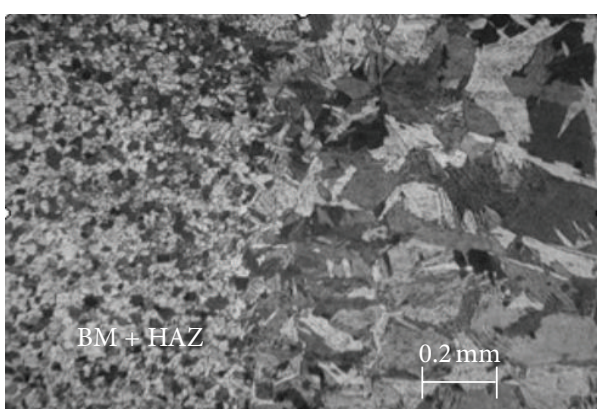

(a)

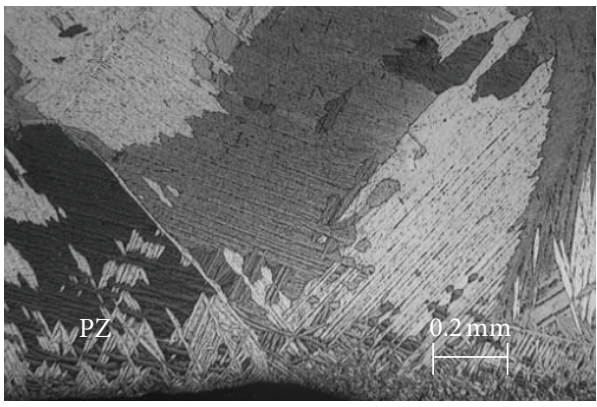

(c)

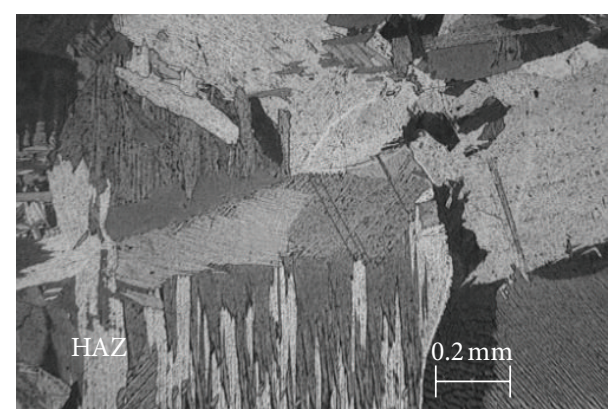

(b)

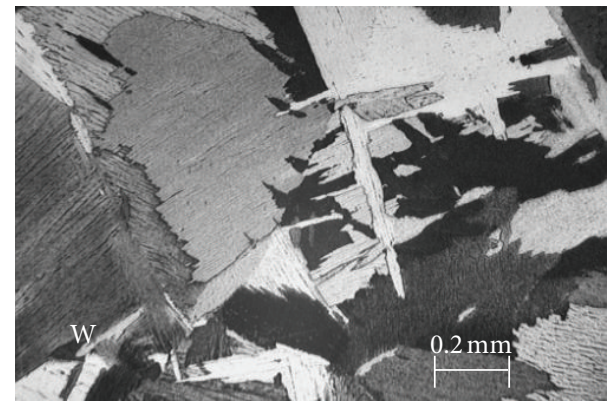

(d)

Figure 7: The microstructure of the welded joint of the thickness $\delta_{1}$ at $I<I_{\mathrm{opt}}$ : the fine-grained structure of the base material after rolling with the phase $\alpha$ coming into the heat-affected zone with thick grains, inclusions of the phase $\beta$ (a); partial or complete recrystallization of the phases $\alpha+\alpha^{\prime}$ and $\beta(\mathrm{b})$; thick grains of the phases $\alpha+\alpha^{\prime}$ and great dislocation density (c); the phase $\alpha^{\prime}$ spines and the deformation twins (d). 


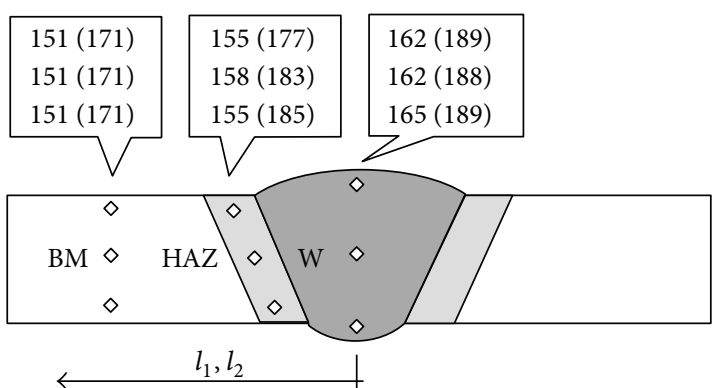

(a)

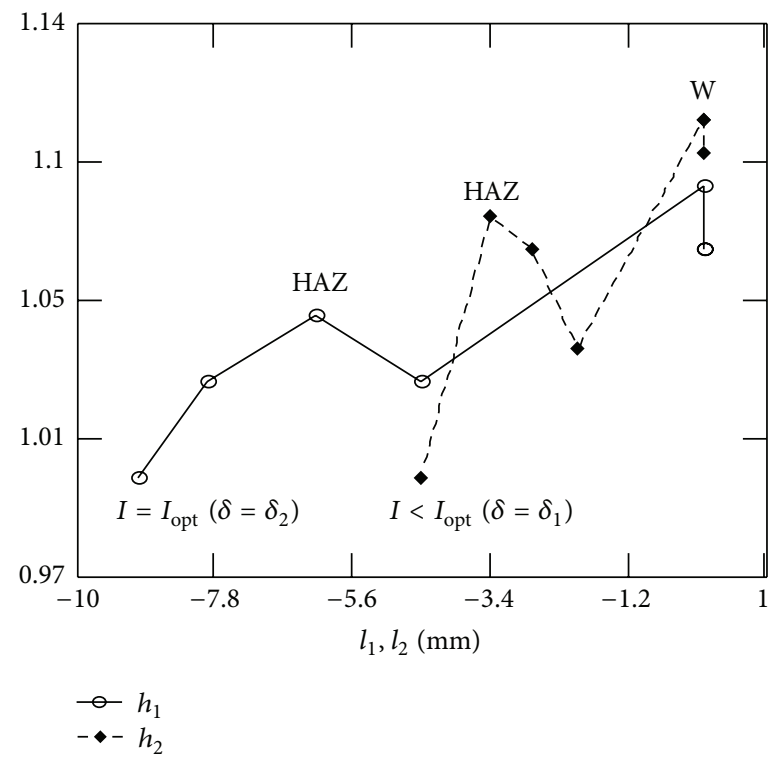

(b)

Figure 8: The hardness numbers $H V 10$ for $I=I_{\text {opt }}\left(\delta=\delta_{2}\right)$ (without parenthesis) and $I<I_{\mathrm{opt}}\left(\delta=\delta_{1}\right)$ (in the parenthesis) (a); the courses of the relative hardness, $h_{1}$ and $h_{2}$ created from the index $H V 10_{\mathrm{HAZ}} / H V 10_{\mathrm{BM}}$ and $H V 10_{\mathrm{W}} / H V 10_{\mathrm{BM}}(\mathrm{b})$.

TABLE 3: The results of the tensile test.

\begin{tabular}{lccccc}
\hline$\delta$ & $\begin{array}{c}\text { Tensile stress } \\
\sigma_{j} \mathrm{MPa}\end{array}$ & Elongat. $\varepsilon_{j} \%$ & \multicolumn{2}{c}{ Relat. coeffic. of } & Frac. \\
& Tensile stress $c_{t}$ & Elongat. $c_{e}$ & \\
\hline$\delta_{2}$ & 415 & 37.8 & 0.82 & 1.11 & $\mathrm{PZ}$ \\
$\delta_{2}$ & 413 & 35.7 & 0.82 & 1.05 & $\mathrm{PZ}$ \\
$\delta_{1}$ & 488 & 16.2 & 0.95 & 0.49 & $\mathrm{~W}$ \\
$\delta_{1}$ & 466 & 11.8 & 0.91 & 0.36 & $\mathrm{~W}$ \\
\hline
\end{tabular}

$\sigma_{j}$ and $\varepsilon_{j}$ are the tensile stress and elongation for joint: $c_{t}=\sigma_{j} / \sigma_{b}, c_{e}=\varepsilon_{j} / \varepsilon_{b}$.

the relative elongation index $c_{e}$ the reciprocal condition functions, that is, $c_{e\left(\delta_{1}\right)}<c_{e\left(\delta_{2}\right)}$. The changes of the strength resulted from the static tensile test are presented in Figure 9. Each of these values exceeds the admissible strength $\sigma_{b}>$ $345 \mathrm{MPa}$ according to ASTM B862 Grade 2. The joints of the thickness $\delta_{1}$ have smaller elongation.

The test results of the bend test are shown in Table 4. Beside mostly positive test results (180 degrees), two negative ones were obtained (58 and 67 degrees). These refer to the
TABLE 4: The results of the bend test.

\begin{tabular}{lcccc}
\hline$\delta$ & $\begin{array}{c}\text { Bend test } \\
\text { kind }\end{array}$ & $\begin{array}{c}\text { Dim. of bend } \\
\text { test spec., mm }\end{array}$ & $\begin{array}{c}\text { Bending angle, } \\
\text { degree }\end{array}$ & Result \\
\hline$\delta_{2}$ & FBB & $25.93 \times 8.01$ & 180 & Positive \\
$\delta_{2}$ & FBB & $26.01 \times 7.94$ & 180 & Positive \\
$\delta_{2}$ & RBB & $25.97 \times 7.98$ & 180 & Positive \\
$\delta_{2}$ & RBB & $26.01 \times 7.93$ & 180 & Positive \\
$\delta_{1}$ & FBB & $14.97 \times 3.01$ & 180 & Positive \\
$\delta_{1}$ & FBB & $15.02 \times 2.98$ & 180 & Positive \\
$\delta_{1}$ & RBB & $14.98 \times 2.98$ & 67 & Negative \\
$\delta_{1}$ & RBB & $15.02 \times 3.01$ & 58 & Negative \\
\hline
\end{tabular}

FBB and RBB mean tensions of weld face and root, respectively.

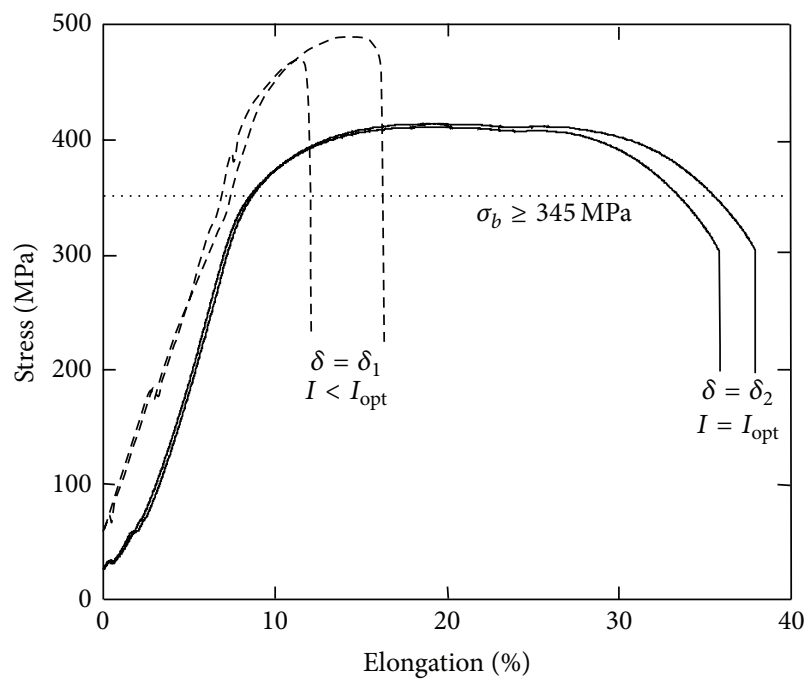

Figure 9: The course of the tensile test for two of the joint thicknesses: $\delta=\delta_{1}\left(I<I_{\text {opt }}\right)$ and $\delta=\delta_{2}\left(I=I_{\text {opt }}\right)$.

joints of the thickness $\delta_{1}$ in which the bend angle on the root side was below the admissible value.

\section{Analysis}

The binary titanium equilibrium systems allow rough understanding of transformations occurring in technical titanium during heating and cooling (Figure 2 and Table 1). In the base material of the welded titanium pipes the phase $\alpha$ with a small quantity of the phase $\beta$ prevails. The thinner joints of the thickness $\delta_{1}$ contained more elements stabilizing the phase $\beta(\mathrm{H}, \mathrm{Fe})$ with a fine structure in the initial state. The filler metal used had a similar chemical content but with a smaller amount of oxygen. The initial material ensured the degrees of strength and plasticity which were greater than the strength and plasticity of the filler metal (Table 2).

The welded joints demonstrated the presence of phases $\alpha, \alpha^{\prime}$, and $\beta$ in the joint area which are typical of technical titanium after welding (Figures 3(a), 3(c), and Figures 5-7). In both cases of the thickness $\delta$ the grain sizes increase towards the weld. The thinner joints in comparison to the thicker 
ones included a greater quantity of the martensite $\alpha^{\prime}$ with deformation twins and the high dislocation density in the joint area. At $\delta_{1}<\delta_{2}$ the quantity of the phase $\alpha^{\prime}$ and smaller grains in the weld result from the cooling rate of both joints, where $v_{1}>v_{2}$ (Figure $3(\mathrm{~b})$ ).

To examine the strength and plasticity of both joint types, the hardness test, the tensile test, and the bend test were carried out. The highest hardness numbers HV10 occurred in the weld and the heat-affected zone (Figure 8) independently of the joint type. These are the areas of the coarsegrained material with an increased brittleness and fractures. Therefore the tensile strength of these areas is smaller than the strength of the base material (Tables 2 and 3 ).

The joints of the thickness $\delta_{1}$ with the smaller argon shield $\left(I<I_{\text {opt }}\right)$ had higher hardness, tensile strength and smaller elongation (Figure 9). The small elongation was convergent with the small bend angle of 58 and 67 degrees for two test pieces (Table 4). Although the tensile strength of those joints exceeds the admissible value in accordance with the standards ASTM B862 Grade $2\left(\sigma_{b}>345 \mathrm{MPa}\right)$, they should be treated as negative joints.

The obtained joint properties in conditions of the increased diffusive activity of oxygen, nitrogen, and hydrogen from the air visually disclosed the colors of the weld. Silver and blue marked admissible and inadmissible colors on the thick and thin joints, respectively. Therefore the joints of the thickness $\delta_{2}$ considered positive had smaller hardness and tensile strength as well as increased elongation.

The quantitative comparison of the joint strength properties includes the relative index of hardness $h$, tensile strength $c_{t}$ (strength), and elongation $c_{e}$ (plasticity) (Figure 8 and Table 3). These indexes satisfy the following conditions: $h_{1}>$ $h_{2}, c_{t\left(\delta_{1}\right)}>c_{t\left(\delta_{2}\right)}$, and $c_{e\left(\delta_{1}\right)}<c_{e\left(\delta_{2}\right)}$.

\section{Conclusions}

The analysis of the test results facilitated the presentation of these conclusions.

(i) Both initial pipes made of technical titanium had basically the structure of the phase $\alpha$ with a small quantity of the phase $\beta$. The welded materials had higher value indicators of the mechanical properties than the filler metal.

(ii) Under the influence of the welding thermal cycle the joints were formed in which the joint area included the phases $\alpha, \alpha^{\prime}$, and $\beta$ typical of technical titanium after welding. In the range of the applied thicknesses $\delta$ the quantity of the martensite $\alpha^{\prime}$ was bigger in the joint of the smaller thickness $\delta_{1}$.

(iii) From the point of view of the acceptance criteria the positive joints had the thickness $\delta_{2}$ and the negative ones the thickness $\delta_{1}$. The positive joints disclosed satisfying hardness, plasticity, and tensile strength within the limit of the recommended standard. The negative joints presented higher hardness and tensile strength and insufficient plasticity which was demonstrated by the bend test. (iv) An inadequate argon shield insufficiently protected the joint against the access of oxygen, nitrogen, and hydrogen from the air. It was conducive to the diffusion of these gases to the joint area, especially to the weld of the highest temperature. Increased ultrasaturation of the phase $\alpha^{\prime}$ with these elements raised the hardness and strength of the joint but decreased its plasticity.

(v) There is a relation between the structure of the welded joints and their mechanical properties. The joints of the thickness $\delta_{1}$ had a greater quantity of the martensite $\alpha^{\prime}$ in the weld and the heat-affected zone than the joints of the thickness $\delta_{2}$. Therefore the thinner joints demonstrated higher hardness and strength but lower plasticity.

(vi) The applied welding of stub pipes of the thickness $\delta_{2}$ by the TIG process can be used for the actual welding of industrial pipelines following certain recommendations. They include the unification of properties in the joint area and the base material.

(vii) For the future it is recommended to anneal joints on the pipelines, if it is possible, in order to obtain optimum mechanical and technological properties and to eliminate welding stresses. Besides, it is recommended to select a filler metal with increased ductility, that is, a reduced content of elements $\mathrm{O}, \mathrm{N}$ and $\mathrm{C}$.

\section{References}

[1] Materials Properties Handbook. Titanium Alloys, ASM International, Materials Park, Ohio, USA, 1994.

[2] "Titanium and Titanium Alloys," in Welding Handbook. vol. 4. Materials and Application, part 2, American Welding Society, 1998.

[3] M. Deters, C. Leyens, and J. Kumpfert, Titan und Titanlegierungen, WILEY-WCH, 1998.

[4] D. Cebon and M. F. Ashby, "Information systems for material and process selection," Advanced Materials and Processes, vol. 157, no. 6, pp. 44-54, 2000.

[5] J. S. Crauman and B. Willey, "Shedding new light on titanium in CPI construction," in Proceedings of the Stainless Steel World Conference, pp. 487-494, KCL, 1999.

[6] V. Madina and S. Azkarate, "Stress corrosion cracking studies of candidate materials for HLW disposal," in Proceedings of the European Federation of Corrosion (Euro-Corr '97), event 208, pp. 737-742, The European Corrosion Congress, Troundheim, Norway, September 1997.

[7] G. A. Young, "Explosion clad works for reactors," Hydrocarbon Engineering, vol. 10, no. 3, pp. 109-110, 2005.

[8] B. Wronka, "Testing of explosive welding and welded joints. Wavy character of the process and joint quality," International Journal of Impact Engineering, vol. 38, no. 5, pp. 309-313, 2011.

[9] S. G. Glazunov and B. A. Kolaczev, Mietallografija Titanovych Splavov, Mietallurgija, Moscow, Russia, 1980.

[10] A. Kelly, G. W. Groves, and P. Kidd, Crystallography and Crystal Defects, John Wiley \& Sons, London, UK, 2nd edition, 2000.

[11] W. A. Baeslack, T. J. Mascorella, and T. J. Kelly, "Weldability of a titanium aluminide," Welding Journal, no. 12, pp. 483-487, 1989. 
[12] R. A. Patterson, P. L. Martin, B. K. Damkroger, and L. Christodoulou, "Titanium aluminide: electron beam weldability," Welding Journal, no. 1, pp. 39-45, 1990.

[13] V. N. Zamkov, S. M. Gurevicz, Institut Elektrosvarki im. E. O. Patona et al., MIetallurgIja $i$ technologIja svarkI tItana $i$ Jevo Splavov, Izdatielstvo Naukova Dumka, Kijev, Ukraine, 1986. 

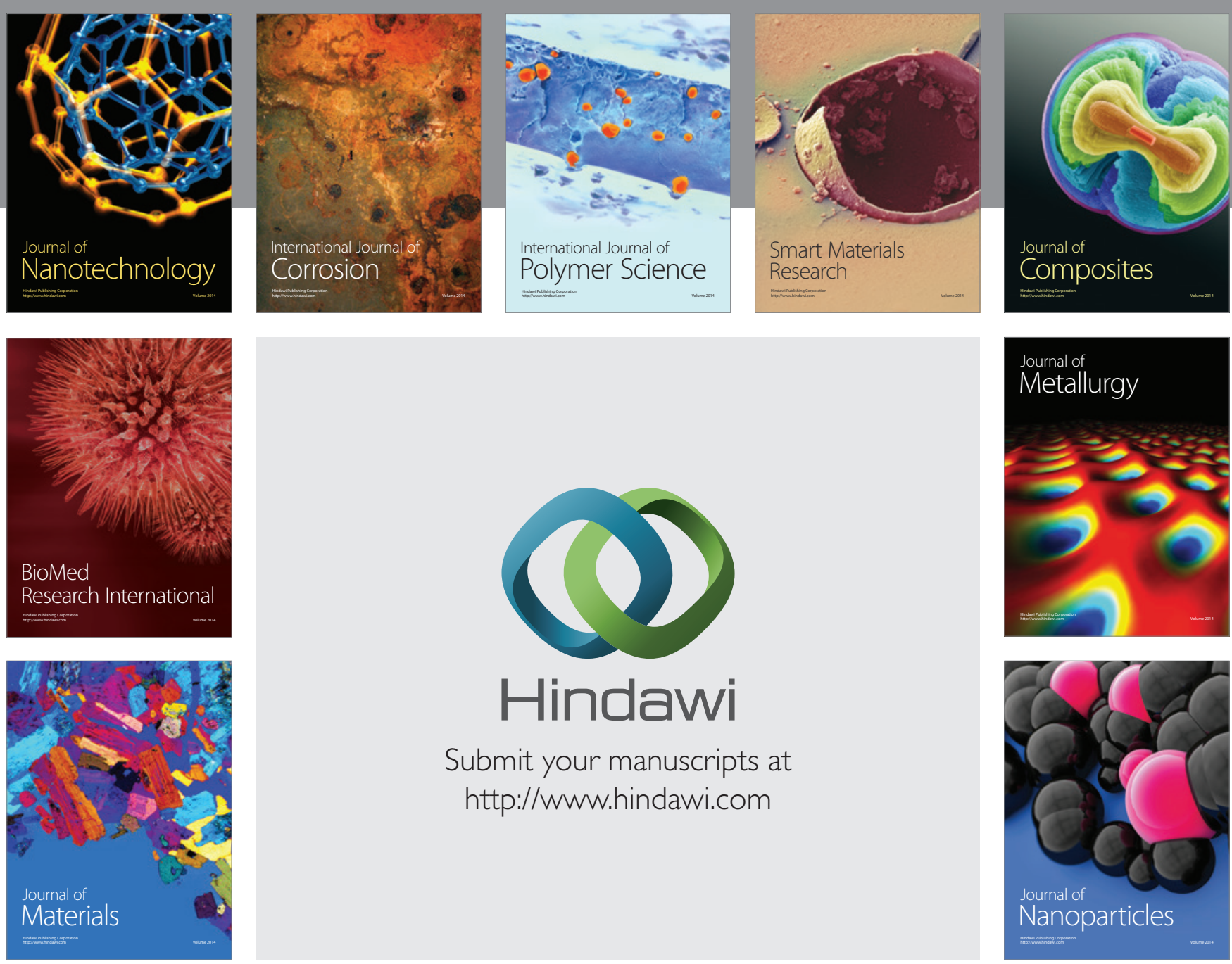

Submit your manuscripts at http://www.hindawi.com
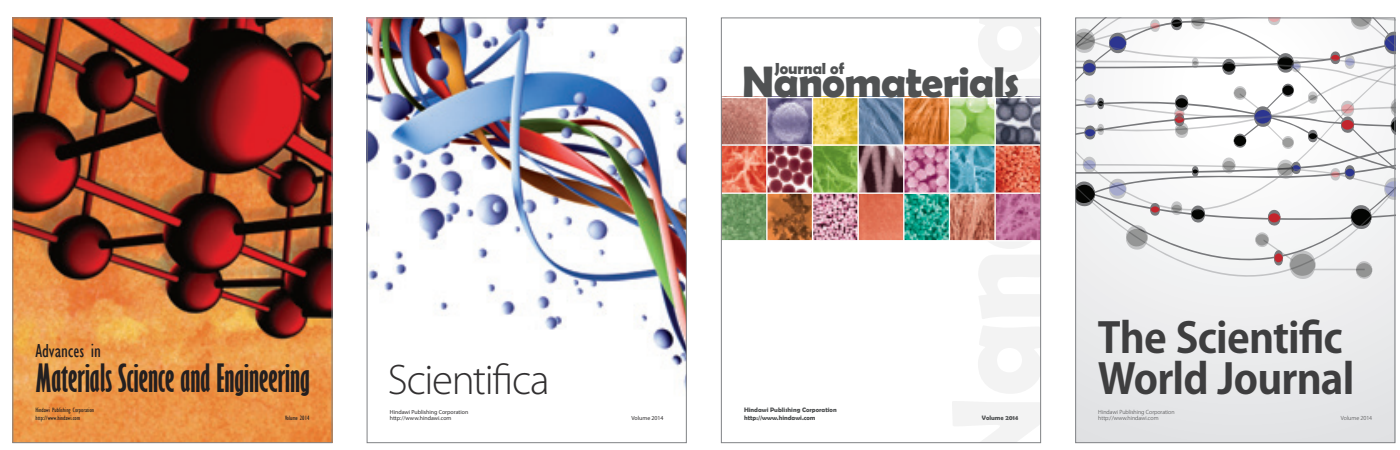

\section{The Scientific World Journal}
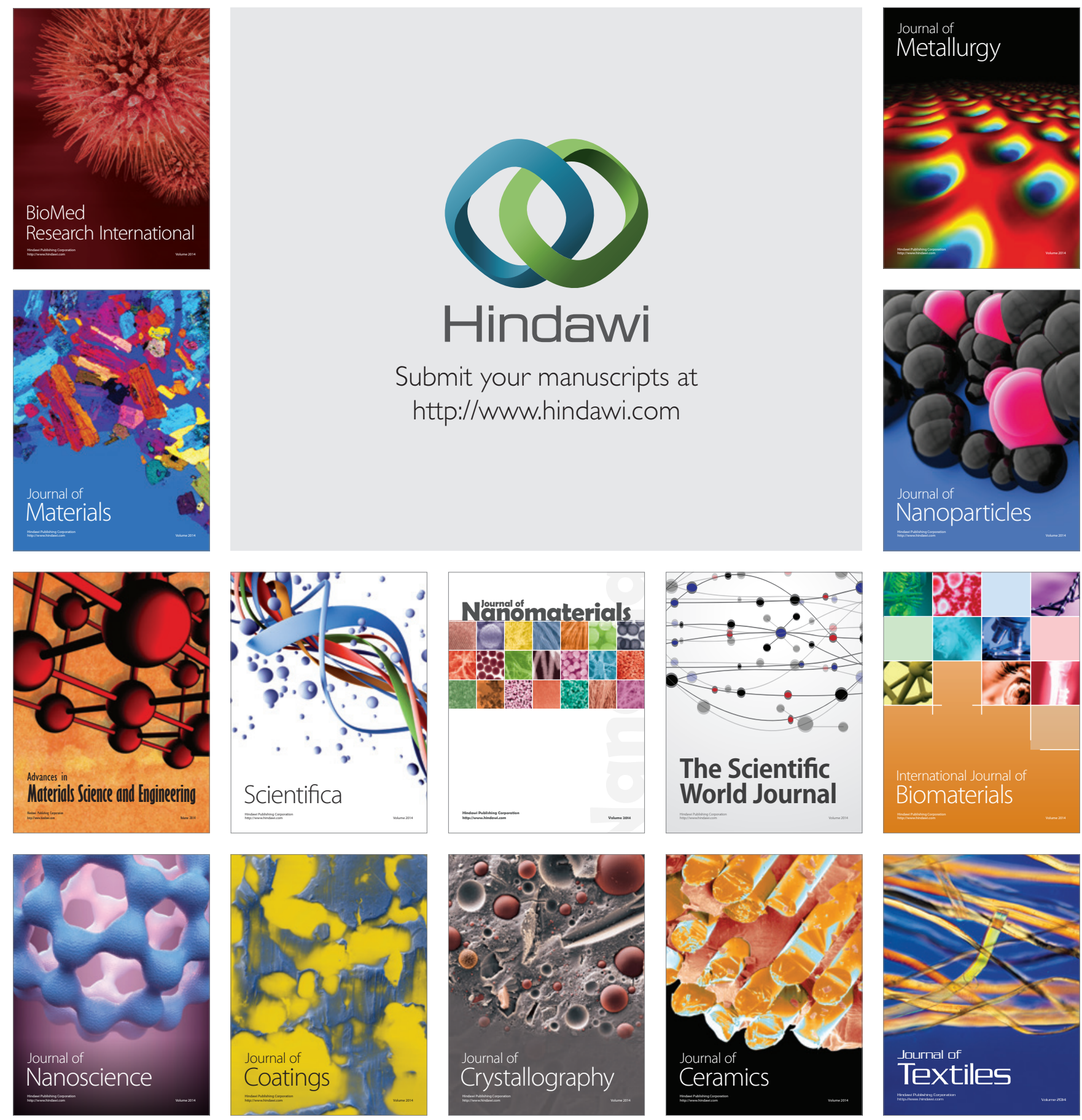